https://doi.org/10.11646/zootaxa.4571.3.9

http://zoobank.org/urn:lsid:zoobank.org:pub:47AC69F3-36C8-42F7-98A5-DC05CB292F40

\title{
A new species of Faronus Aubé, 1844, endemic to Malta (Coleoptera, Staphylinidae, Pselaphinae)
}

\author{
SERGEY A. KURBATOV ${ }^{1}$, DAVID MIFSUD ${ }^{2,4} \&$ GIORGIO SABELLA ${ }^{3}$ \\ ${ }^{1}$ Museum of Entomology, All-Russian Plant Quarantine Center, Pogranichnaya 32, Bykovo 140150, Russia. \\ E-mail: pselaphidae@yandex.ru \\ ${ }^{2}$ Institute of Earth Systems, Division of Rural Sciences and Food Technology, University of Malta, Msida MSD 2010, Malta. \\ E-mail: david.a.mifsud@um.edu.mt \\ ${ }^{3}$ Dipartimento di Scienze Biologiche, Geologiche ed Ambientali dell'Università-sezione Biologia Animale-via Androne 81, I- \\ 95124 Catania, Italia. E-mail: sabellag@unict.it \\ ${ }^{4}$ Corresponding author. E-mail: david.a.mifsud@um.edu.mt
}

\begin{abstract}
Faronus rica sp. nov. endemic to Malta is described and illustrated, and placed in the Faronus hispanus species group. Faronus rica sp. nov. is closely related to F. siculus Fiori, 1913, an endemic species to Sicily, and they can be distinguished based on morphological features highlighted in the present work.
\end{abstract}

Key words: Faronini, taxonomy, Mediterranean

\section{Introduction}

The pselaphines of the Maltese Islands have been the subject of a recent study carried out by Sabella $\&$ Mifsud (2016) with 14 species recorded. Of these, only Amaurops mifsudi Poggi, 1999 is endemic to the Maltese Islands, whereas Tychus opuntiae (Schmidt-Göbel, 1836) and Euplectus bonvouloiri siculus Raffray, 1910 are endemic to both Sicily and Malta.

Sabella \& Mifsud (2016) did not find species of the genus Faronus Aubé, 1844 in the Maltese Islands. They pointed out that the absence of such species in Malta is very difficult to justify due to the fact that they are (i) mainly associated with Mediterranean maquis and garigue habitat types, which are both well-represented in the Maltese archipelago, and (ii) generally such species are relatively common throughout the Mediterranean region with several species present in North Africa, Sicily and the circum-Sicilian islands.

Faronus Aubé, 1844 represents a western Palaearctic genus with 32 described species mainly occurring in the Mediterranean Basin (Schülke \& Smetana 2015). In November 2017, following intensive field investigations, two specimens of Faronus were finally collected in Malta. The species was proved to be new to science and is described here.

\section{Material and methods}

The type material of the present study is deposited in the Museum d'histoire Naturelle de Genève, Switzerland (MHNG).

The body length, excluding the antennae, is measured from the anterior clypeal margin to the posterior margin of the last abdominal tergite. The length and width of the body parts were measured between points of maximum extension, e.g. the head length is measured between the anterior clypeal margin and the posterior margin of the neck; the head width includes the eyes; the elytral length is measured along the sutural line, and the elytral width includes the width of both elytra. The abdominal segments are numbered from the first visible segment onwards, 
i.e. from tergite 1 (fourth segment) and ventrite 1 (third segment). The nomenclature follows that proposed by Chandler (2001) and morphological terminology follows Beutel \& Leschen (2005). The genitalia were mounted in Canada balsam on an acetate label, which are pinned with the specimen.

\section{Taxonomy}

\section{Faronus rica sp. nov.}

(Figs 1, 2, 5, 7, 9, 11)

Type material. Holotype, ô (MHNG). MALTA, Wied Babu, 50 m, 23.xi.2017, sifting litter of Ceratonia siliqua (S. Kurbatov). Paratype, 1 ( (MHNG); same locality of holotype, 24.xi.2017, sifting litter of Ceratonia siliqua (D. Mifsud \& G. Sabella).

Description. Male. Body length $1.75 \mathrm{~mm}$, entirely reddish brown with yellowish palpi and legs. Relatively dense pubescence of long and flattened golden setae on head, pronotum, elytra and abdomen; other setae, yellowish and suberect present on sides of antennae, palpi and legs. Tegument smooth and shiny.

Head triangular, wider $(0.35 \mathrm{~mm})$ than long $(0.22 \mathrm{~mm})$. Wide and deep longitudinal median frontal sulcus, which starts from the frontal lobe and forks in the middle; then bifurcates towards the base of the occipital region. Temples slightly shorter than eyes and marginally protruding, each forming an angle of about $70^{\circ}$ with the longitudinal axis of the head, and ending in an annular organ. Eyes well developed and protruding with 32-33 facets. Antennae with cylindrical scape about twice as long as wide, pedicel as long as wide, antennomere 3 is the smallest of the flagellum and wider than long, antennomere 4 slightly longer than wide, antennomeres 5-6 as long as wide, antennomeres 7-8 slightly wider than long. The club is not so distinct having antennomeres 9-10 wider than long and wider than preceding articles; antennomere 11 slightly wider than 10 and slightly longer than wide.

Pronotum distinctly wider $(0.41 \mathrm{~mm})$ than long $(0.31 \mathrm{~mm})$, widest in the middle; lateral discal fovea, lateral antebasal fovea, medial antebasal fovea, and outer antebasal fovea present and distinct; antebasal sulcus lacking. Disc convex in the middle with a horseshoe-shaped impression, its transversal part (including the median antebasal fovea) distinctly impressed whereas the two longitudinal branches very weakly impressed; the latter bearing four adjacent foveae.

Elytra wider $(0.51 \mathrm{~mm})$ than long $(0.40 \mathrm{~mm})$ and longer than pronotum, and gradually widen from the base to the apex. Two basal foveae; sutural stria reaching apical part of elytra with three very small adjacent foveae; discal stria reaching about two thirds of elytral length. Humeri not distinctly protruding followed by a weak lateral depression. Hind wings absent.

Abdomen distinctly longer than both pronotum and elytra together, the first three visible tergites having the same length. Posterior margin of $2^{\text {nd }}$ ventrite slightly raised in the middle; posterior margin of $3^{\text {rd }}$ ventrite strongly raised and forming an open cup-shaped structure in the middle (Fig. 1); the central part of the $4^{\text {th }}$ ventrite depressed having the middle part of posterior margin raised as a form of lamina at $90^{\circ}$ in such a way that it fits into the cupshaped structure just described and apically slightly curved posteriorly (Fig. 2).

Legs with protibia widest in the middle (Fig. 9) with mesal margin sinuate in distal half, apically having a short rounded process; mesotibiae slightly enlarged in the apical third with a similar terminal process as in the protibiae.

Aedeagus (Fig. 7) length $0.33 \mathrm{~mm}$, with well-developed slender parameres widest in the middle, left paramere with two apical setae and right paramere with one; two additional medial setae are also present towards the centre of each paramere. Median part of aedeagus wide and distinctly sclerotized with a pointed apical part on the right; apical membrane equipped with multiple small spiniform processes.

Female. Body (Fig. 5) length $1.80 \mathrm{~mm}$ entirely light reddish with yellow palpi and legs. Pubescence and tegument as in male.

Head as in male, wider $(0.31 \mathrm{~mm})$ than long $(0.21 \mathrm{~mm})$. Eyes well developed and protruding with $25-27$ facets. Antennae similar to those of male.

Pronotum similar to that of male, also for the foveae system on dorsal surface, wider $(0.36 \mathrm{~mm})$ than long $(0.31$ $\mathrm{mm})$.

Elytra wider $(0.44 \mathrm{~mm})$ than long $(0.33 \mathrm{~mm})$, similar to those of male, only less distinctly enlarged from base to apex. 
Abdomen as in male in dorsal view, and with unmodified abdominal ventrites.

Legs unmodified.

Telisternite as in figure 11.

Comparative notes. Faronus rica sp. nov. belongs to the F. hispanus species group (Sabella 1993) characterized by males having secondary sexual characters on abdominal ventrites, aedeagus with sinuate parameres, well sclerotized median part bearing multiple small spiniform processes apically. The group currently accommodates F. hispanus Saulcy, 1870, known from Portugal (Algarve), Spain (Catalonia, Valencia, Andalusia) and northern Algeria; F. insularis Sainte-Claire Deville, 1908, endemic to Sardinia and circum-sardinian islands and southern Corsica; F. siculus Fiori, 1913, endemic to Sicily, F. insignis Besuchet, 1958, known from the Balearic Islands (Majorca and Minorca), and F. rica sp. nov. endemic to Malta.
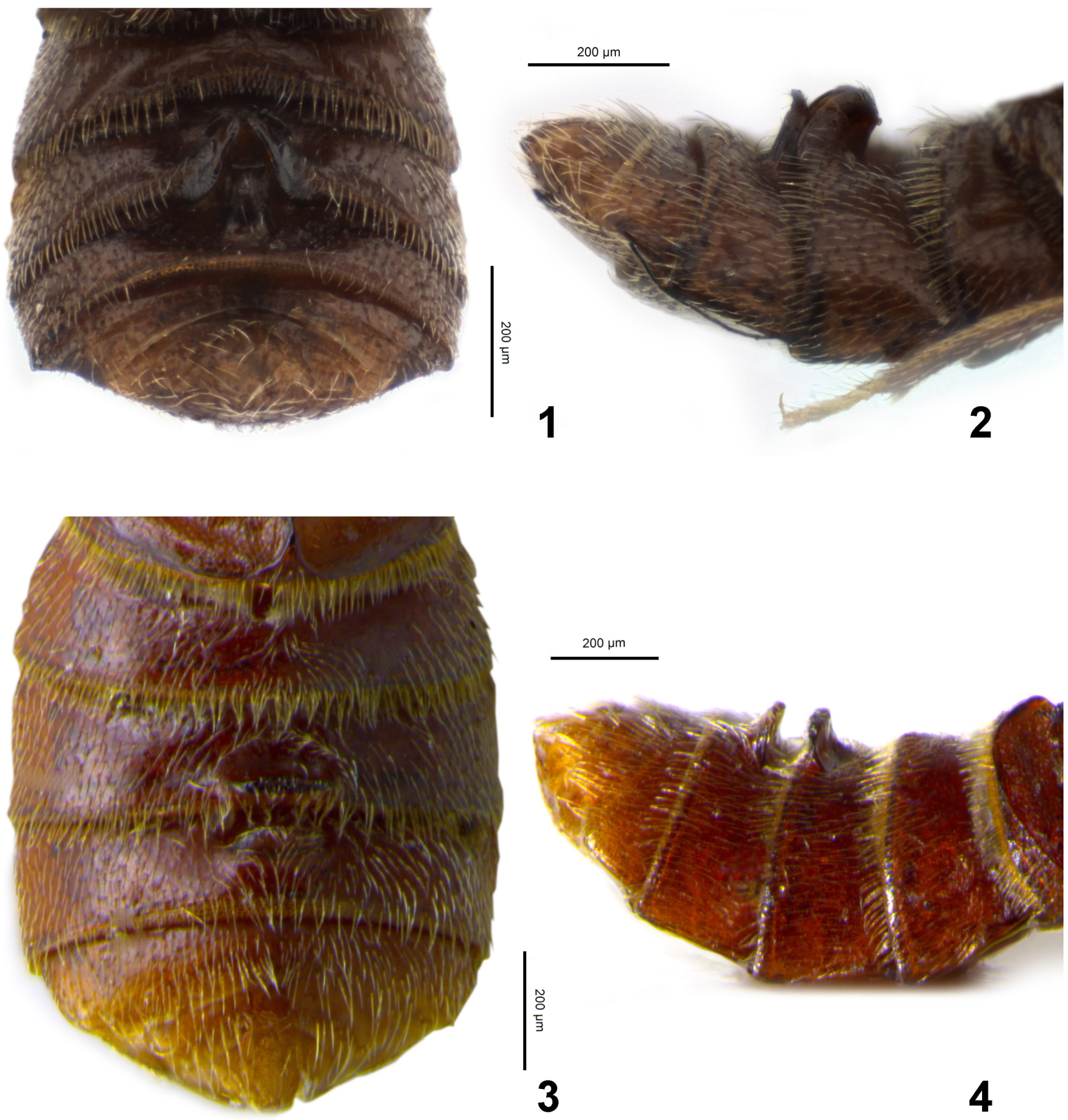

FIGURES 1-4. Abdominal ventrites (dorsal and lateral view): 1, 2—Faronus rica sp. nov.; 3, 4—F. siculus. 

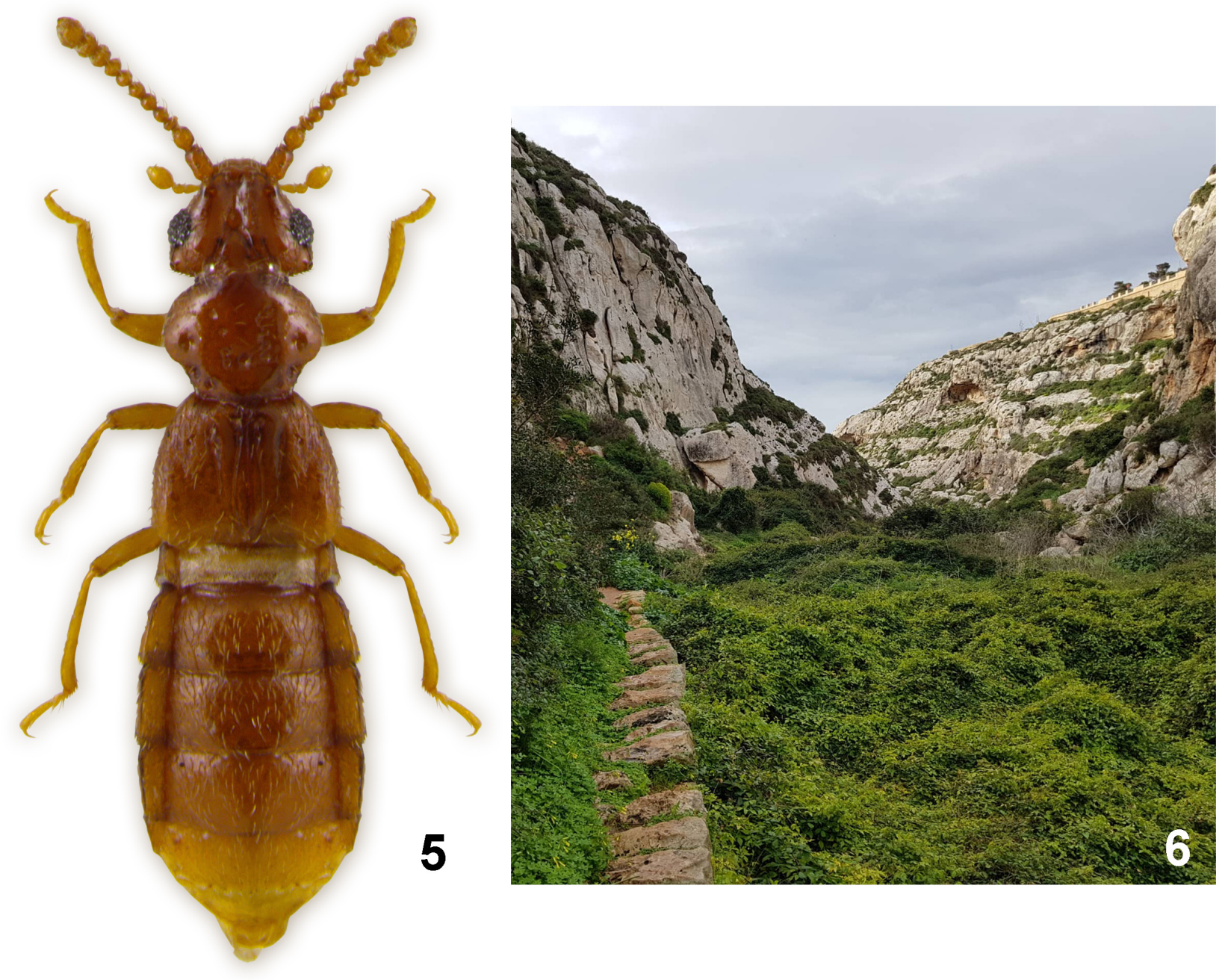

FIGURES 5-6. 5- Habitus of female, Faronus rica sp. nov.; 6-Wied Babu, type locality of F. rica sp. nov.

Faronus rica sp. nov. is closely related to $F$. siculus with which many morphological characters are shared. It differs from this species on the basis of the following features: (i) protibia of male widest in the middle with mesal margin sinuate in distal half (cfr. Figs. 9, 10); (ii) left side of median part of aedeagus pointed apically (cfr. Figs. 7, 8); and (iii) the highly modified $3^{\text {rd }}$ and $4^{\text {th }}$ ventrites having a strongly raised open cup-shaped structure in the middle (on $3^{\text {rd }}$ ventrite) and a $90^{\circ}$ raised lamina (on $4^{\text {th }}$ ventrite) which fits into the cup-shaped structure and apically curved posteriorly (cfr. Figs.1-4). Females of both species are impossible to discriminate on the basis of morphological features. Some morphological differences in the apical region of the telisternite were found and these are illustrated in figures 11 and 12.

Ecological notes. The two specimens of Faronus rica sp. nov. were collected in November by sifting leaf litter under Ceratonia siliqua, in a valley system at $50 \mathrm{~m}$ of altitude, along with numerous specimens of Tychus opuntiae (Schmidt-Goebel, 1836). Wied Babu (Fig. 6) is a fine example of a river valley and creek. The area is rich in endemic species such as the National Plant for Malta (Cheirolophus crassifolius) for which Wied Babu is the type locality.

Etymology. This species is dedicated to Yves and Patricia Rica, a French family residing in Malta who are always very helpful and contribute financially for entomological research work carried out by the corresponding author in Malta. They offered free accommodation to many delegates present at the $4^{\text {th }}$ International Congress of Biodiversity held in Malta (13-16 ${ }^{\text {th }}$ November 2017) and thereafter, this provided the right opportunity for the present authors to do intensive field work and to discover the new species which we gladly and proudly dedicate to them. 

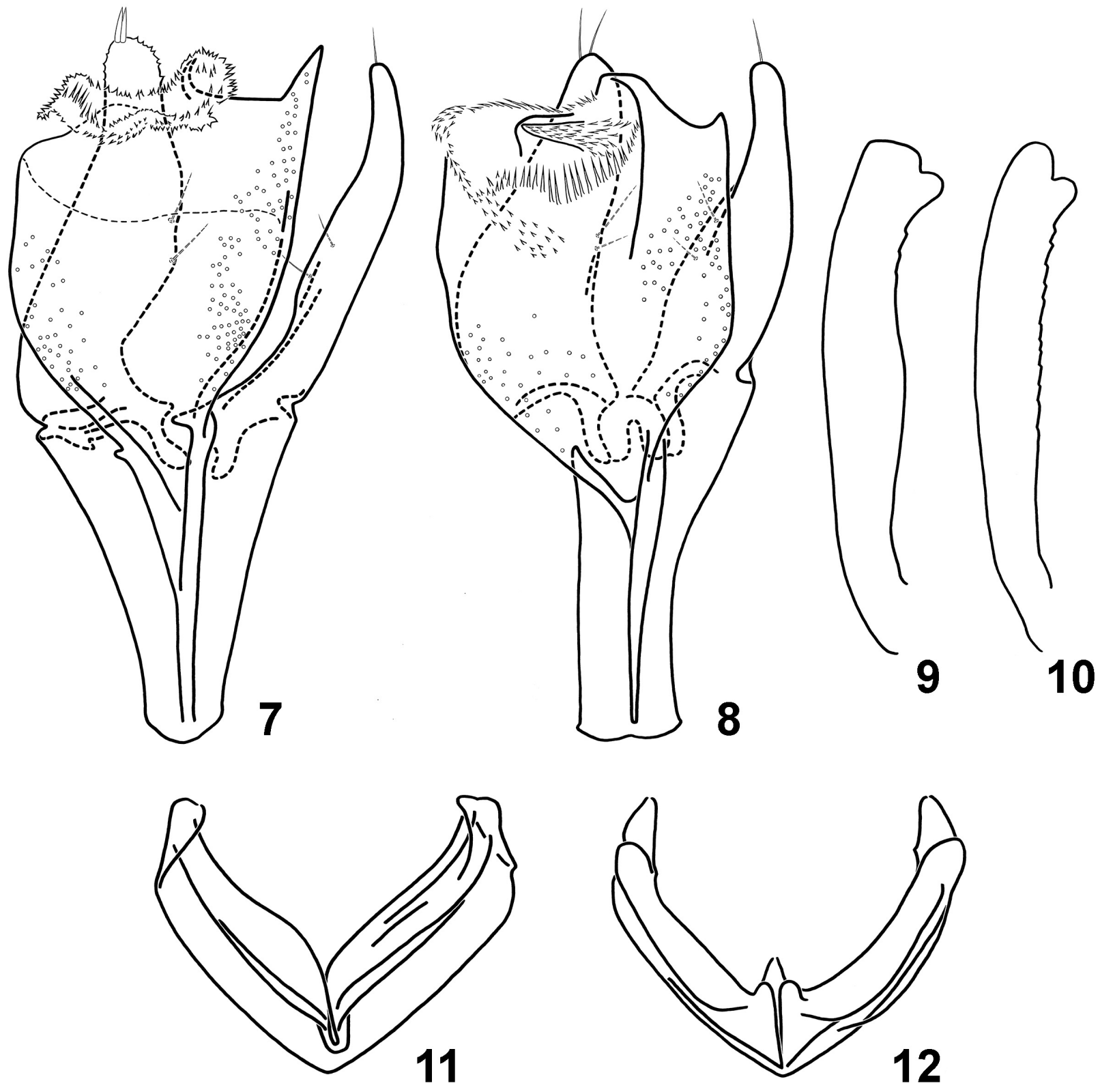

FIGURES 7-12. 7, 8-Aedeagi; 9, 10 - protibiae of males; 11, 12-female telisternites. (7, 9, 11-Faronus rica sp. nov.; 8, 10, 12-Faronus siculus)

\section{Acknowledgments}

Many thanks to our friend and colleague Giulio Cuccodoro (MHNG) for taking photographs of male secondary sexual characters, and Fabio Viglianisi for the photo of the female of Faronus rica sp. nov.

\section{References}

Beutel, R.G. \& Leschen, R.A.B. (Eds.) (2005) Handbuch der Zoologie/Handbook of Zoology, Vol. IV, Arthropoda: Insecta, Part 38, Coleoptera, Beetles, Vol. I: Morphology and Systematics. de Gruyter, Berlin, xii + 578 pp.

Chandler, D.S. (2001) Biology, morphology, and systematics of the ant-like litter beetles of Australia (Coleoptera: 
Staphylinidae: Pselaphinae). Memoirs on Entomology, International, 15, 1-560.

Sabella, G. (1993) Studies on the Pselaphidae of Sicily. VI. On the sicilian species of the genus Faronus with a redescription of F. siculus Fiori, 1913 and F. vitalei Raffray, 1913. (Coleoptera Pselaphidae). Spixiana, 16 (2), 145-156.

Sabella, G. \& Mifsud, D. (2016) The Pselaphinae (Coleoptera, Staphylinidae) of the Maltese Archipelago. Bulletin of the Entomological Society of Malta, 8, 7-34.

https//doi.org/10.17387/BULLENTSOCMALTA.2016.01

Schülke, M. \& Smetana, A. (2015) Catalogue of Palaearctic Coleoptera Pselaphinae. In: Löbl, I. \& Löbl, D. (Eds.), Catalogue of Palaearctic Coleoptera. Hydrophiloidea-Staphylinoidea 2 vols. Revised and Updated Edition, Volume 2.1., Brill Books, xxvii + 1702 pp. 